EMBRYARIDDLE
Aeronautical University

SCHOLARLY COMMONS
Journal of Aviation/Aerospace

Education \& Research

Volume 30

Number 1 JAAER 2021

Article 4

2021

\title{
Job Demands and Job Resources Among Western Airline Cabin Crews: A Comparative Study of Canadian, German, and French Flight Attendants
}

\author{
Sarah Nogues \\ University of Québec-Téluq, sanogues@teluq.ca \\ Diane-Gabrielle Tremblay \\ University of Québec-Téluq, dgtrembl@teluq.ca \\ Sari Mansour \\ Université Téluq, sari.mansour@teluq.ca
}

Follow this and additional works at: https://commons.erau.edu/jaaer

Part of the Human Resources Management Commons, and the Labor Relations Commons

\section{Scholarly Commons Citation}

Nogues, S., Tremblay, D., \& Mansour, S. (2021). Job Demands and Job Resources Among Western Airline Cabin Crews: A Comparative Study of Canadian, German, and French Flight Attendants. Journal of Aviation/Aerospace Education \& Research, 30(1). https://doi.org/10.15394/jaaer.2021.1882

This Article is brought to you for free and open access by the Journals at Scholarly Commons. It has been accepted for inclusion in Journal of Aviation/Aerospace Education \& Research by an authorized administrator of Scholarly Commons. For more information, please contact commons@erau.edu. 


\section{Introduction}

For the past 30 years, the airline industry has been increasingly competitive and will surely remain so in the post-pandemic context, as airlines will be even more pressured for costs. With a forecast of 118 billion USD global net losses for year 2020, industry experts "expect airline operating margins to be under pressure in 2021 since airlines will continue to have difficulty to downsize their costs to match with lower revenues" (International Air Transport Association [IATA], 2020, p. 3). While low-cost airlines may recover faster due to their flexible business model, major carriers appear more severely impacted (Sobieralski, 2020). As a result, airlines have been proceeding to major cuts in labor with an estimated $13 \%$ reduction in employment between 2020-2021 (Sobieralski, 2020) and wage and benefit cuts are expected for the remaining employees (von Nordenflycht \& Gittell, 2013) with those in charge of passenger handling hardest hit by this workforce reduction, spurring aviation scholars to warrant the allocation of resources to this category of workers (Sobieralski, 2020).

Flight attendants are frontline workers in charge of onboard security, safety and customer service. They have to perform several tasks requiring physical and psychological efforts during flight duty periods (FDP), which may last up to 17 hours in Canada (Transport Canada, n.d.) and 16 hours in Europe (European Commission, 2013). Research has consistently proven their vulnerability to a variety of health issues (Griffiths \& Powell, 2012), and there is evidence that many aspects of their job have become more difficult over the years with work schedules that have become more and more disruptive and unpredictable (Shalla, 2004), passengers that are increasingly demanding and misbehaving (Hu, Hu, \& King, 2017), and progressive reductions in the number of flight attendants onboard, as illustrated in the past few years in Canada by a controversial government decision to take the established ratio of 1 flight attendant per 40 
passengers to 1 per 50 (Canadian Union of Public Employees [CUPE], 2017). As flight attendants risk being faced with ever more difficult working conditions in the wake of Covid-19, what can airline management do to keep these frontline employees from exhaustion and other adverse outcomes? The present study addresses this timely question drawing on a cross-country comparison of pre-pandemic perceived job demands and job resources among flight attendants employed at major Western airlines.

\section{Flight Attendant Job Demands}

Job demands are the "physical, social, or organizational aspects of the job that require sustained physical or psychological effort are therefore associated with certain physiological and psychological costs" (Demerouti, Bakker, Nachreiner, \& Schaufeli, 2001, p. 501). They may be further classified as temporal (e.g., time pressure), physical (e.g., job strain) or social (e.g., emotional labor). Flight attendants spend most of their work time standing up, walking back and forth in aircraft aisles, and manipulating heavy trolleys. They do this despite a generalized state of fatigue due to long and changing working hours (Chung \& Chung, 2009; MacDonald et al., 2003 ) with a means of 5.7 hours of sleep per workday according to U.S. data (Avers \& Johnson, 2011). Moreover, they perform an emotional labor requiring them to control their facial expressions or alter their own internal feelings (Hochschild, 1983) to project positive emotions to passengers, doing so for prolonged periods of time within the confined space of the cabin, which constitutes a major precursor to emotional exhaustion and burnout (Jeung, Kim, \& Chang, 2018; Kim \& Wang, 2018). They are also prone to conflicts between work and family roles (Chung \& Chung, 2009; MacDonald et al., 2003) in turn leading to job stress (Chen \& Kao, 2011). Therefore, flight attendants are subject to high temporal, physical and social job demands. 
Excessive job demands may, however, be buffered or decreased by certain job resources (Demerouti et al., 2001).

\section{Flight Attendant Job Resources}

Job resources are the physical, psychological, social, or organizational aspects of the job, which may reduce job demands, aid in achieving work goals, or stimulate personal growth, learning, and development (Demerouti et al., 2001, p. 501). Flight attendant studies have shown that organizational resources such as options for career development (Chen \& Kao, 2012) as well as stress management programs reduced the adverse effects of emotional labor (Jeung et al., 2018). Social support from colleagues, supervisors, and support from outside of work tend to reduce anger, job dissatisfaction, fatigue, conflict in relations and stress for flight attendants (MacDonald et al., 2003), and a recent study found that peer support had the highest impact on burnout for service workers (Kim \& Wang, 2018). However, another study yielded contradictory results with scheduling satisfaction (i.e., temporal resource) found as the most influent job resource regarding flight attendants' emotional exhaustion, compared to no effect for peer support (Schiffinger \& Braun, 2020). Organizational job resources may come in the form of "high performance work practices," which although aimed at improving employee performance are increasingly considered for their impact on employee well-being (van de Voorde, van Veldhoven, \& Peccei, 2017). These practices impact employee outcomes through distinct pathways and should be distinguished depending on their enhancing either employee ability (e.g., training), motivation (e.g., promotion, work-life policies) or opportunity (e.g., empowerment) to perform (Jiang, Lepak, Hu, \& Baer, 2012). A recent study revealed in this respect that motivation-enhancing job resources positively influence psychological well-being, while ability-enhancing and opportunity-enhancing job resources are linked with higher social 
and physical well-being (Khoreva \& Wechtler, 2018). However, another study showed that flexible hours (motivation) and decision-making (opportunity) increase stress (Topcic, Baum, \& Kabst, 2016). Therefore, it is not clear what kind of resources companies should implement to safeguard employee health and performance.

In the aftermath of Covid-19, airline management is urged to find solutions to at least try to mitigate the expected negative consequences of this shock on their frontline employees (Sobieralski, 2020) along with their possible hazardous effects on public safety, as flight attendants are less likely to adopt safety behaviors when confronted with high job demands and low job resources (Chen \& Chen, 2014). However, present research is not clear about which types of job resources best prevent emotional exhaustion and burnout (Demerouti et al., 2001), what the relative impact of social resources such as peer support (Kim \& Wang, 2018) when compared to organizational resources (Schiffinger \& Braun, 2020), and whether so-called high performance work practices lead to increased or decreased well-being outcomes (van de Voorde et al., 2017). A comparison of perceived job demands, job resources, burnout and stress between different groups of flight attendants may bring an important perspective to these findings. Indeed, while all flight attendants are expected to endure the consequences of the Covid crisis in the long term (Sobieralski, 2020), airlines have agency in "formulating diverse responses within the same institutional context" (Becker-Ritterspach, Saka-Helmhout, Lange, \& Geppert, 2017, p. 25), and have a certain leeway in how to respond to external events (Belobaba, Swelbar, \& Odoni, 2016). However, this may not necessarily translate into big differences among flight attendants in terms of how they experience their job, which is otherwise highly regulated and standardized, especially so at legacy airlines with more rigid business models (Sobieralski, 2020) and strong union representation. A cross-country analysis will allow us to examine the relative 
influence of the institutional context in this matter. The present study thus reports on job demands and job resources as perceived by three groups of flight attendants employed at regular airlines in Canada, France and Germany. Given that French and German airlines are both subjected to the EU regulatory context, we would expect less differences between these two groups, and more contrasted results between Canadian participants and their European counterparts. In this article, we will answer recent calls to pursue investigating the importance of specific job demands-resources (Schiffinger \& Braun, 2020) and exploring possible trade-offs between certain (AMO-enhancing) organizational practices and well-being outcomes (van de Voorde et al., 2017).

\section{Methods}

Participants were reached through union listings. The online questionnaire contained validated items retrieved from various sources addressing employee stress, work-family conflict, organizational support, and service work and was sent to 4,500 members between October 2015 and April 2016. A total of 1,740 flight attendant questionnaires were received, representing a response rate of 38.67\%. Only answers from Canada (504), France (720) and Germany (440) were included in the present study for coherence purposes, as they are Western developed countries with comparable socioeconomic standards, and as both German and French groups fall within the same EU regulatory environment. Four regular airlines are represented (including two in Canada) employing a number of flight attendants ranging from 2,000 to 35,000 at the time of the study. Some findings from in-depth interviews with flight attendants and pursers (i.e., onboard leaders) from Canada (41) and Germany (18) are mentioned in the discussion section to add perspective to quantitative results. In keeping with the reviewed literature, the present study investigated temporal job demands (i.e., work hours, time pressure), physical job demands (i.e., 
physiological symptoms, stress) and social job demands (i.e., work-home interferences, signs of burnout). Job resources include ability-enhancing (i.e., training), extrinsic (i.e., work-life policies, flexible schedule) and intrinsic (i.e., respect) Motivation-enhancing as well as Opportunity-enhancing (i.e., empowerment) HR practices (Jiang et al., 2012); psychological and physical job resources through perceived management commitment to stress prevention and priority given to employee psychological heath; and social job resources (i.e., support from coworkers, purser, nonwork).

\section{Results}

A great proportion of participants across the three countries reported that their working conditions had recently deteriorated, especially so in France (88\%), followed by Canada (77\%), and Germany (64\%). A vast majority also reported that their workload had increased in the past year, especially among French flight attendants (86\%), followed by Germany (82\%), and Canada (78\%). There was thus a strong, shared feeling that job demands had increased and that job resources had decreased in recent times. However, some differences were observed regarding perceived job demands and job resources between the three groups.

\section{Job Demands}

Canadian participants worked the longest hours since few flew less than 70 hours each month (11\%) compared to their German (26\%) and French (45\%) counterparts. In terms of perceived time pressure, however, while the French flew the less, they were the most (70\%) to report feeling rushed and not having enough time compared to Germany (60\%) and Canada (59\%). Aches and pains, such as sore back, headache, stiff neck or stomachache, were reported in high proportions across the three countries, amounting to $72 \%$ for Canada and Germany and as much as $83 \%$ for France. French flight attendants were also a vast majority to report work- 
home interferences (89\%), compared to German (76\%) and Canadian (60\%) participants who were the least likely to report so, despite working the longest hours. Canadian flight attendants also stood out by reporting the lowest stress levels (56\%) compared to the French (62\%) and German (64\%). However, German participants were the least likely to report working too hard on their job on every FDP (8\%), compared to French (17\%) and Canadian (21\%) participants. They were also less inclined to feel emotionally drained from work at least once a week (17\%) compared to $22 \%$ in France and $23 \%$ in Canada, appeared significantly less likely to report feeling burnout as a result from their jobs at least once a week (15\%) compared to $26 \%$ of Canadian and $38 \%$ of French participants and were the least likely to present signs of disengagement by treating passengers as impersonal objects (Figure 1). In addition, while only 8\% of Canadian and 7\% of French participants reported never feeling burned-out, 19\% of German participants reported so. Thus, the German group reported the lowest levels of emotional job demands and burnout, while overall perceived job demands were almost systematically highest in the French group. 


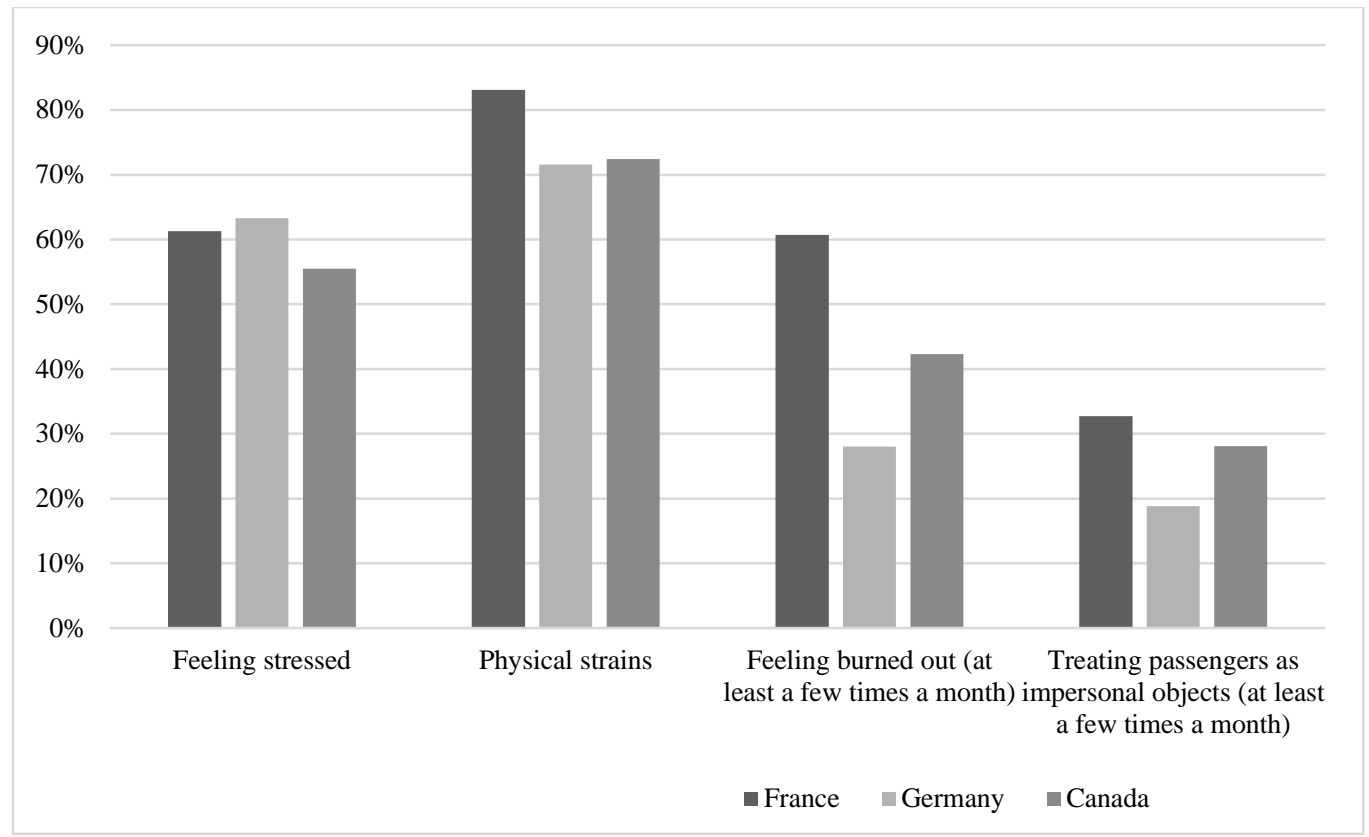

Figure 1. Stress and burnout among cabin crews in France, Germany, and Canada.

\section{Job Resources}

Important differences were observed in the availability of organizational resources, where only $13 \%$ of French participants thought that their employer invested in their abilities with training outside mandatory or promotion courses, compared to $35 \%$ in Canada and $44 \%$ in Germany. In terms of opportunity to perform, a substantial number of German participants (67\%) felt empowered to solve passenger problems, while only $38 \%$ of Canadians and $26 \%$ of French participants felt so. Notable variations were also found regarding extrinsic motivationenhancing job resources, as 39\% of Canadian flight attendants reported being able to benefit from measures supporting work-life balance, compared to $22 \%$ in Germany and $20 \%$ in France. Most strikingly, $62 \%$ of Canadian participants reported the availability of flexible hours, compared to $35 \%$ of German and $15 \%$ of French participants. Regarding intrinsic motivation resources, most participants across the three countries did not feel valued or respected by their superiors, nor thought that their promotion prospects were adequate regarding their efforts and 
achievement (Figure 2), with slightly better results in Germany. Similarly, very few participants perceived that management showed support for stress prevention, with somewhat better results in Germany (18\%) compared to Canada (11\%) and France (10\%). German participants were also less inclined to believe that the psychological well-being of employees is not a priority in the company (29\%) in comparison to Canadian (44\%) and French (56\%) participants. Finally, in contrast to job resources from management, participants across the three countries reported high levels of peer support where $83 \%$ of Canadian, $82 \%$ of French, and $75 \%$ of German flight attendants either agreed or strongly agreed that their colleagues helped them carry out their tasks. Social support from pursers (i.e., onboard leaders) and from outside of work was about equally high across the three country groups (Figure 2). 


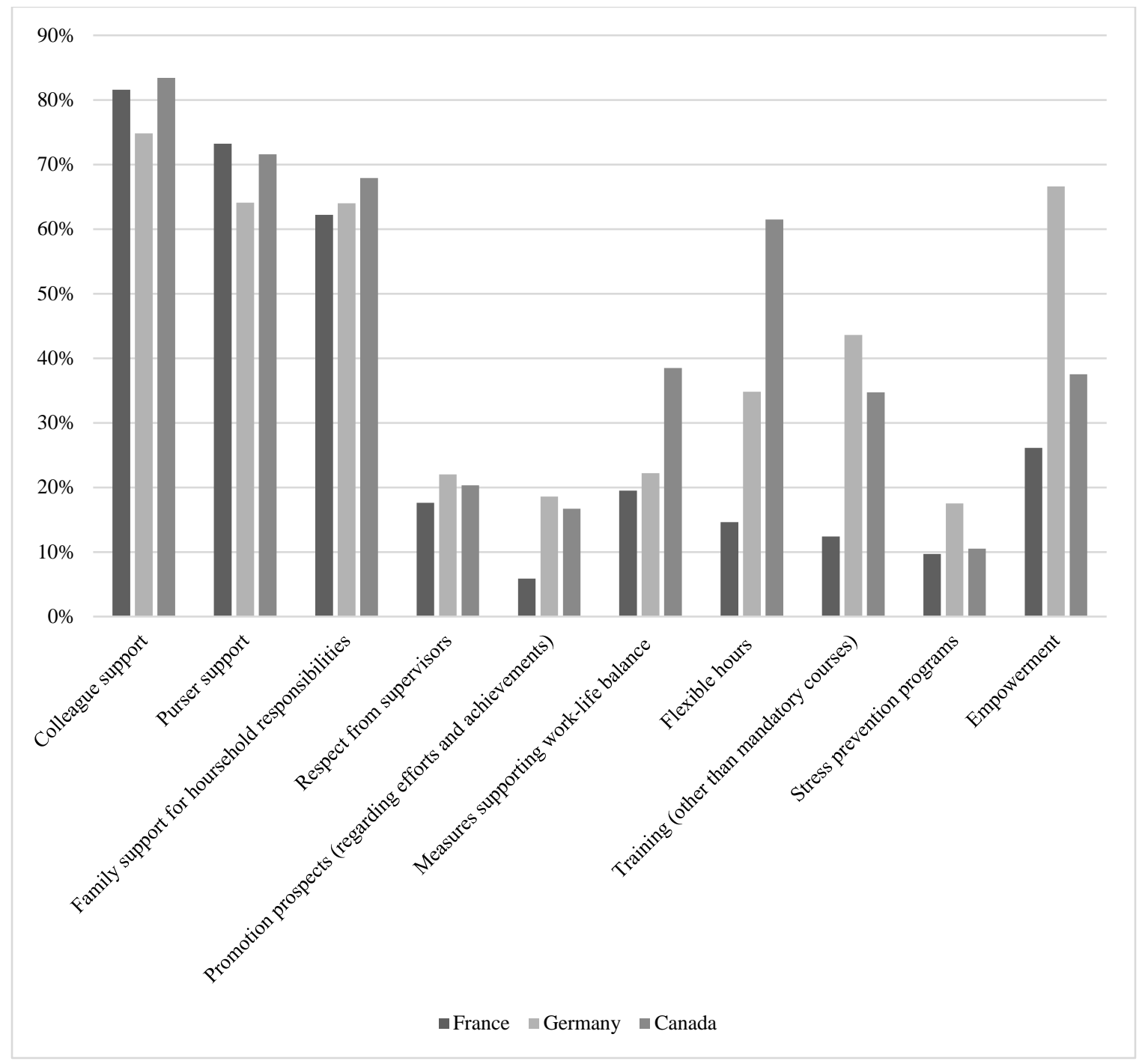

Figure 2. Job resources among cabin crews in France, Germany, and Canada.

\section{Concluding Remarks}

Our results reveal differences in perceived job demands and job resources between flight attendants employed at Canadian, French, and German airlines. Contrary to our expectations, the most contrasted differences were found between our German and French group despite sharing a more similar institutional context. This shows the importance of airline agency in HRM (Becker-Ritterspach et al., 2017; Belobaba et al., 2016), which entails that the Covid crisis might impact flight attendants differently depending on the types of job resources accessible in their 
work environment. Contributions to the job demands-resources (Demerouti et al., 2001) and AMO-enhancing practices (Jiang et al., 2012; van de Voorde et al., 2017) literatures are presented below.

A main statement is the consistent highest perceived job demands and lowest levels of job resources among the French group, except for social support. While French flight attendants benefitted from high levels of social support (peer, purser, family), organizational resources were consistently poor compared to the Canadian and German groups, while they reported the highest physical and temporal demands and were the most likely to experience burnout. Conversely, while reporting the lowest levels of social support, the German group was the least likely to feel emotionally drained and burned-out, which suggests that social support is the most influent resource in reducing burnout (Kim \& Wang, 2018), and supports recent findings reporting that peer support does not impact emotional exhaustion (Schiffinger \& Braun, 2020). For the Canadian group, perceived time pressure as well as work-home interferences were the lowest, despite reporting the highest number of hours worked. This supports the finding that high temporal job resources significantly alter temporal job demands (Schiffinger \& Braun, 2020). Indeed, the Canadians were the most likely to report the presence of flexible hours and measures helping with work-life balance. However, it was in Germany that burnout levels were the lowest. Therefore, the highest presence of temporal resources in Canada did not result in lowest signs of emotional exhaustion, despite previously identified as its strongest antecedent (Schiffinger \& Braun, 2020). This may be explained by the fact that Germany overall presented the highest level of resources when considering resource allocation in representing the three categories of Ability, Motivation, and Opportunity to perform, thus covering the several pathways through which employee outcomes and well-being can be impacted (Jiang et al., 2012). While Canadians scored 
high on extrinsic motivation-enhancing resources (e.g., flexible hours, measures supporting work-life balance), German participants indicated slightly higher levels of intrinsic motivationenhancing resources such as promotion perspectives, which can be explained by the fact that in this airline promotions are granted by evaluating one's performance and leadership abilities while it is mostly based on seniority in Canada, as our qualitative findings revealed. The German group was also better represented in terms of Ability and Opportunity job resources (i.e., training and empowerment), therefore presenting a variety of job resources not only focused on reducing job demands but also resources which "aid in achieving work goals, or stimulate personal growth, learning and development" (Demerouti et al., 2001, p. 501). However, while Ability and Opportunity practices have been found to reduce job strain (Khoreva \& Wechtler, 2018), stress levels were the highest in Germany, despite more stress prevention programs. The particularly high level of empowerment found in this country may, as others found, increase pressure related to decision-making and, therefore, increase stress (Topcic et al., 2016). Our results thus suggest the existence of trade-offs between aspects of employee well-being (i.e., stress and burnout) in response to the presence of certain high performance work practices (van de Voorde et al., 2017). Still, our results suggest that it is better to have more resources than less (e.g., France), despite the possible occurrence of such trade-offs. Future studies should pay attention to which kind of job resources are likely to mitigate the particularly high physical demands (Chung \& Chung, 2009; MacDonald et al., 2003; Avers \& Johnson, 2011) and physiological costs (Griffiths \& Powell, 2012) faced by flight attendants.

The overall greater perception of job resources found in Germany may be explained by an industrial relations structure marked by a partnership approach with employees and unions, as opposed to a liberal market economy such as Canada with "union relations that tend to focus 
more on wage minimization than on productivity-enhancement" (Becker-Ritterspach et al., 2017). Still, our results showed less differences between the German and the Canadian group than between the German and the French group, despite comparable working conditions (i.e., flight time limitations), in that French and German flight attendants are both subjected to the norms of the European Union Aviation Safety Agency. This indicates that perceived job demands may vary despite similar institutional contexts, further highlighting management leeway in HRM (Becker-Ritterspach et al., 2017; Belobaba et al., 2016). French flight attendants were more likely to feel rushed, report work-home interferences, work too hard on their job and feel burned-out than their German counterparts and were more likely to report so than their Canadian counterparts, despite lower employee protection in this type of economy (BeckerRitterspach et al., 2017). Moreover, Canadian flight attendants were the least stressed and reported the least work-home interferences. Still, our data was collected before the implementation of the new flight attendant per passenger ratio, which has been highly debated by the union, fearing that an "increased workload leading to greater fatigue may impair a flight attendant's judgment and efficiency during an emergency evacuation" (CUPE, 2017, p. 18) ${ }^{1}$. Given the numerous health issues faced by flight attendants (Avers \& Johnson, 2011; Griffiths \& Powell, 2012), flight attendant health and safety concerns constitute a "basis for many of the collectively bargained work-rules for flight attendants" (CUPE, 2017, p. 2). While collective agreements and regulations already limit flight attendant job demands in the three countries represented, our results suggest that airlines implementing job resources covering employee ability, motivation, and opportunity to contribute (Jiang et al., 2012) overall present the lowest perceived job demands and burnout. While all major airlines are severely impacted by the Covid-

\footnotetext{
${ }^{1}$ Union also reports unsafe work rules with, under certain circumstances, reduced exit door coverage resulting from this ratio (CUPE, 2017).
} 
Journal of Aviation/A erospace Education \& Research, Vol. 30, No. 1 [2021], Art. 4

19 shock (IATA, 2020; Sobieralski, 2020), those fostering a variety of organizational resources may be more apt to mitigate its adverse consequences on employee health, performance, and on public safety. 


\section{References}

Avers, K., \& Johnson, W. (2011). A review of Federal Aviation Administration fatigue research. Aviation Psychology and Applied Human Factors, 1(2), 87-98. https://doi.org/10.1027/2192-0923/a000016

Becker-Ritterspach, F., Saka-Helmhout, A., Lange, K., \& Geppert, M. (2017). Exploring the interaction of firm-level change and national institutional environments in shaping employment and union relations: A comparative case study of four European airlines. The International Journal of Human Resource Management, 30(2), 276-305. https://doi.org/10.1080/09585192.2016.1276092

Belobaba, P. B., Swelbar, W. S., \& Odoni, A. R. (2016). Critical issues and prospects for the global airline industry. In P. Belobaba, A. Odoni, \& C. Barnhart (Eds.), The global airline industry ( $2^{\text {nd }}$ ed., pp. 487-500). New York, NY: John Wiley \& Sons.

Canadian Union of Public Employees (CUPE). (2017, April 6). Full submission by the Canadian Union of Public Employees (CUPE) to House of Commons, Standing Committee on Transport, Infrastructure and Communities. Retrieved from https://cupe.ca/cupessubmission-house-commons-standing-committee-transport-infrastructure-andcommunities

Chen, C.-F., \& Chen, S.-C. (2014). Investigating the effects of job demands and job resources on cabin crew safety behaviors. Tourism Management, 41, 45-52. https://doi.org/10.1016/j.tourman.2013.08.009

Chen, C-.F., \& Kao, Y.-L. (2011). The antecedents and consequences of job stress of flight attendants - Evidence from Taiwan. Journal of Air Transport Management, 17(4), 253255. https://doi.org/10.1016/j.jairtraman.2011.01.002 
Chung, C.-T., \& Chung, U.-L. (2009). An exploration of quality of life and related factors among female flight attendants. Journal of Nursing Research, 17(3), 212-220. https://doi.org/10.1097/JNR.0b013e3181b2558f

Demerouti, E., Bakker, A. B., Nachreiner, F., \& Schaufeli, W. B. (2001). The job demandsresources model of burnout. Journal of Applied Psychology, 86(3), 499-512. https://doi.org/10.1037/0021-9010.86.3.499

European Commission. (2013). Pilot and crew fatigue - frequently asked questions. Retrieved from https://ec.europa.eu/commission/presscorner/detail/en/MEMO_13_854

Griffiths, R. F., \& Powell, D. M. C. (2012). The occupational health and safety of flight attendants. Aviation, Space, and Environmental Medicine, 83(5), 514-521. https://doi.org/10.3357/ASEM.3186.2012

Hochschild, A. R. (1983). The managed heart. Berkeley, CA: University of California Press. Hu, H.-H. “S.”, Hu, H. Y., \& King, B. (2017). Impacts of misbehaving air passengers on frontline employees: Role stress and emotional labor. International Journal of Contemporary Hospitality Management, 29(7), 1793-1813. https://doi.org/10.1108/IJCHM-09-2015-0457

International Air Transport Association (IATA). (2020). Economic performance of the airline industry. Retrieved from https://www.iata.org/en/iata-repository/publications/economicreports/airline-industry-economic-performance-june-2020-report

Jeung, D.-Y., Kim, C., \& Chang, S.-J. (2018). Emotional labor and burnout: A review of the literature. Yonsei Medical Journal, 59(2), 187-193. https://doi.org/10.3349/ymj.2018.59.2.187 
Jiang, K., Lepak, D. P., Hu, J., \& Baer, J. C. (2012). How does human resource management influence organizational outcomes? A meta-analytic investigation of mediating mechanisms. Academy of Management Journal, 55(6), 1264-1294. https://doi.org/10.5465/amj.2011.0088

Khoreva, V., \& Wechtler, H. (2018). HR practices and employee performance: The mediating role of well-being. Employee Relations, 40(2), 227-243. https://doi.org/10.1108/ER-082017-0191

Kim, S., \& Wang, J. (2018). The role of job demands-resources (JDR) between service workers' emotional labor and burnout: New directions for labor policy at local government. International Journal of Environmental and Public Health, 15(12), 1-31. https://doi.org/10.3390/ijerph15122894

MacDonald, L. A., Deddens, J. A., Grajewski, B. A., Whelan, E. A., \& Hurrell, J. J. (2003). Job stress among female flight attendants. Journal of Occupational and Environmental Medicine, 45(7), 703-714. https://doi.org/10.1097/01.jom.0000071509.96740.dd

Schiffinger, M., \& Braun, S. M. (2020). The impact of social and temporal job demands and resources on emotional exhaustion and turnover intention among flight attendants. Journal of Human Resources in Hospitality \& Tourism, 19(2), 196-219. https://doi.org/10.1080/15332845.2020.1702867

Shalla, V. (2004). Time warped: The flexibilization and maximization of flight attendant working time. The Canadian Review of Sociology and Anthropology, 41(3), 345-368. https://doi.org/10.1111/j.1755-618X.2004.tb00782.x 
Sobieralski, J. B. (2020). COVID-19 and airline employment: Insights from historical uncertainty shocks to the industry. Transportation Research Interdisciplinary Perspectives, 5, 1-9. https://doi.org/10.1016/j.trip.2020.100123

Topcic, M., Baum, M., \& Kabst, R. (2016). Are high-performance work practices related to individually perceived stress? A job demands-resources perspective. The International Journal of Human Resource Management, 27(1), 45-66.

https://doi.org/10.1080/09585192.2015.1043136

Transport Canada. (n.d.). Canadian aviation regulations (CARs) - Part VII - Commercial air services. Retrieved from https://www.tc.gc.ca/eng/civilaviation/regserv/cars/part7standards720-2153.htm

van de Voorde, K., van Veldhoven, M. V., \& Peccei, R. (2017). Exploring trade-offs between employee well-being and organizational performance: The role of human resource management. Human Resource Management Journal (call for papers), 3.

von Nordenflycht, A., \& Gittell, J. H. (2013). Context, process, and outcomes of collective bargaining in the U.S. airline industry. In H. R. Stanger, A. C. Frost, \& P. F. Clark (Eds.), Collective bargaining under duress: Case studies of major U.S. industries, pp. 9-43. 